\title{
DOMÍNIO DE MERCADO DE CLIENTES: GERENCIANDO RELACIONAMENTOS COM COMPRADORES, INTERMEDIÁRIOS E CONSUMIDORES
}

\section{CLIENT MARKET DOMAIN: MANAGING RELATIONSHIP WITH BUYERS, INTERMEDIARIES AND CONSUMER}

\author{
Cindy Johanna Ibarra González \\ Mestranda do Programa de Pós-graduação em Engenharia Mecânica \\ Universidade Federal de Santa Catarina \\ cindyibarra@nedip.ufsc.br

\section{Cláudia Regina Ziliotto Bomfá} \\ Doutoranda do Programa de Pós-graduação em Engenharia de Produção \\ Pesquisadora do $\mathrm{CNPq}$ \\ Universidade Federal de Santa Catarina \\ claudia@deps.ufsc.br

\section{Olga Regina Cardoso} \\ Professora do Programa de Pós-graduação em Engenharia de Produção \\ Universidade Federal de Santa Catarina \\ cardosoolga@uol.com.br

\section{Jane Iara Pereira Da Costa} \\ Professora do Programa de Pós-graduação em Administração \\ UDESC - Universidade do Estado de Santa Catarina \\ costajane@uol.com.br
}

Resumo: O presente artigo apresenta a questão do domínio de mercado de clientes, sendo abordada a conceituação dos subgrupos deste domínio: compradores diretos, intermediários e consumidores finais. Em seguida, realizada-se uma explanação da segmentação destes subgrupos, e finalmente, analisa-se a unidade da tomada de decisões (DMU) e mencionam-se as estratégias de aquisição e retenção de clientes, mediante alguns estudos de caso que ilustram as situações mencionadas. Concluise que, com a ampliação do papel dos clientes nos relacionamentos, os fornecedores ou provedores de serviços têm se preparado para servi-los e atender suas necessidades na troca pelo valor (lucrativo), em forma de dinheiro e negócios repetidos, permitindo o benefício mútuo no relacionamento. 
Palavras-chave: Marketing de relacionamento. Domínio de mercado de clientes. Segmentação de mercado.

\begin{abstract}
This works deals with the issue of the client market domain, exploring its subgroups meaning: primary buyers, intermediary and final consumers. Thereafter, it describes this subgroups segmentation, analyses the decision taking unit (DMU) and makes reference to the strategies for obtain and maintain the clients based on these matter case studies. Finally the research concludes that the suppliers or services providers have been preparing themselves for achieve the client's expectations changing it for value (profit), like money and frequent deals, with the clients market participation increase, therefore allowing the mutual benefit.
\end{abstract}

Key - Words: Relationship Marketing. Client market domain. Market segmentation

\title{
1. INTRODUÇÃO
}

(...) não se pode apenas fingir que se está cuidando do cliente. È preciso cuidar mesmo. E não adianta dar passos tímidos nesta direção. Você precisa tornar concreto suas declarações verbais de interesse pelo cliente, fazendo mudanças substanciais que tragam para ele um genuíno valor agregado. (RAPP; COLLINS, 1999).

A abertura de novos mercados tem ampliado a concorrência entre as empresas, tornando os clientes cada vez mais exigentes. Neste sentido, a exigência por produtos e serviços de alta qualidade a preços competitivos tem sido parte da filosofia das empresas que desejam manter-se no mercado. Esse grande desafio empresarial só será vencido se as empresas tornarem-se orientadas para o cliente, pois é isto que determina sua satisfação e fidelidade. Segundo Swift (2001, p.01), "com a ampliação do papel do cliente nos relacionamentos, os fornecedores ou provedores de serviço têm se preparado para servi-lo e atender suas necessidades na troca pelo valor (lucrativo), em forma de dinheiro e negócios repetidos".

A competitividade entre as empresas tem exigido dos clientes que 0 fornecedor ofereça flexibilidade, disponibilidade, criatividade e preço vantajoso. Para tanto, novas técnicas estão sendo utilizadas com 0 intuito de descobrir características que evidenciem os desejos, preferências e comportamentos dos clientes.

Neste contexto, cabe a este trabalho refletir a respeito do tema "Domínio do mercado de clientes", sendo que primeiramente será abordada a conceituação dos subgrupos deste domínio: compradores diretos, intermediários e consumidores 
finais. Em segundo lugar, será realizada uma explanação da segmentação destes subgrupos. Em terceiro lugar, será analisada a unidade da tomada de decisões (DMU). Em quarto lugar, serão mencionadas as estratégias de aquisição e retenção de clientes, e finalmente, alguns estudos de caso que ilustrem as situações mencionadas.

\section{DOMÍNIO DE MERCADO DE CLIENTES}

\subsection{Conceituação}

De acordo com Peck (1999), o domínio de mercado de clientes compreende três grupos: compradores diretos, intermediários e consumidores finais, conforme ilustra a figura 1.

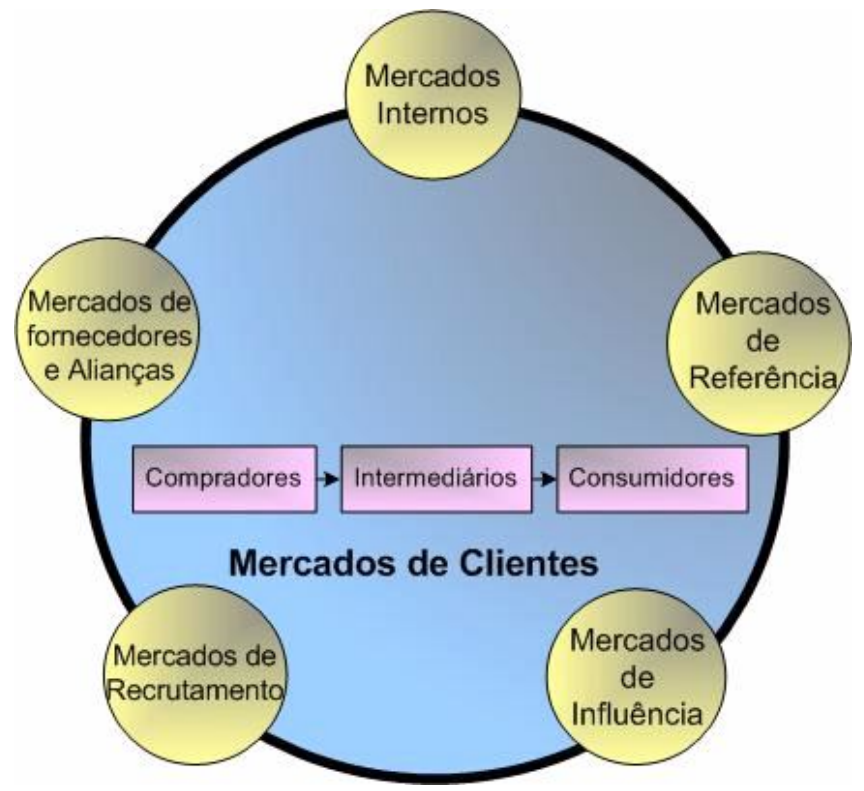

Figura 1 - O domínio do mercado de clientes.

Fonte: Peck et al. (1999, p.35)

Os subgrupos do mercado de clientes são conceituados por Peck (1999) da seguinte forma:

Os compradores são aqueles que compram diretamente do fabricante (atacadista). Os intermediários compram do atacadista (varejista) e os consumidores são os que compram do varejista, sendo estes os indivíduos do final do canal. 
Com o objetivo de ilustrar melhor os subgrupos adaptou-se uma ilustração prática do cultivo e venda de morangos (figura 2), na qual o fornecedor vende diretamente ao feirante, que na sua vez vende à sorveteria, que desenvolve o produto para o consumidor final. Salienta-se que o termo "cliente" é utilizado por Peck (1999) referindo-se a todos estes subgrupos.
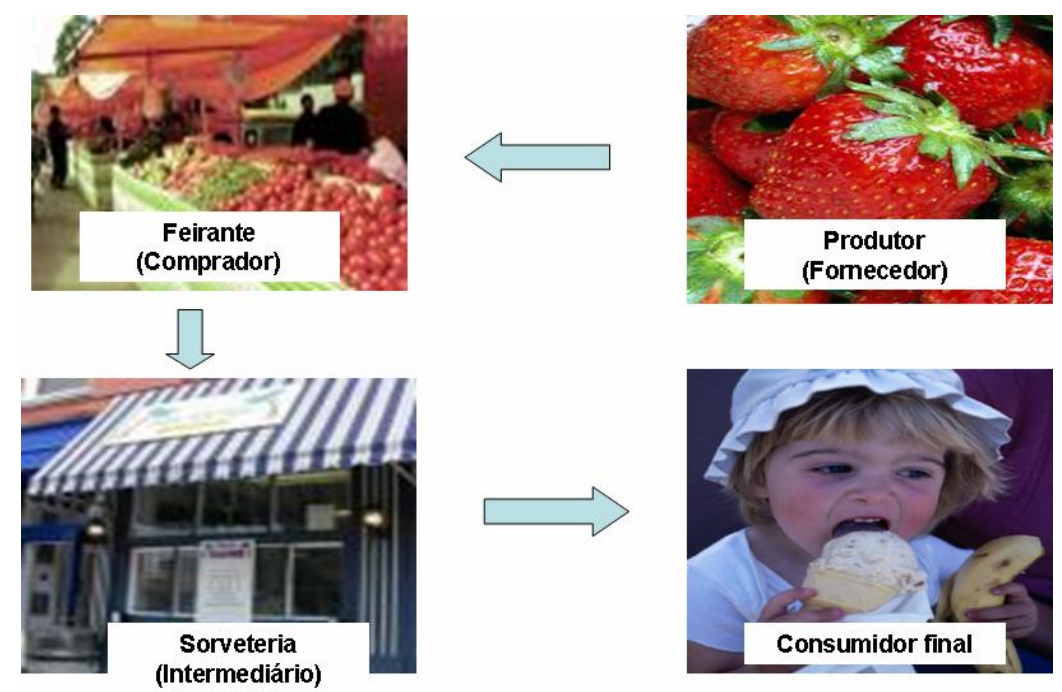

Figura 2 - Exemplo prático de mercado de clientes.

Fonte: autoras

Neste contexto, cabe ressaltar que Swift (2001, p.3-4) define como múltiplos os seguintes tipos ou grupos de clientes:

O cliente de varejo que compra o produto ou o serviço final, normalmente, um indivíduo ou uma família. As empresas para empresas, cliente que compra o seu produto (ou serviço) e adiciona ao mesmo ao produto que fabrica, para venda a outro cliente ou empresa. O canal/distribuidor/franquia, pessoa ou organização que não trabalha diretamente para a empresa, não estando na folha de pagamento, que compra o produto para vender ou para utilizá-lo como seu representante/ponto de venda nessa área. E, finalmente, o cliente interno, pessoa ou unidade de negócio dentro de uma empresa, que precisa de um determinado produto ou serviço para obter sucesso nos próprios objetivos de negócio.

Diversos autores de marketing apresentam uma gama extensiva de opções de distribuição, pela qual uma empresa pode optar para servir ao consumidor final, criando intermediários adicionais dentro do canal, conforme pode ser visualizado na figura 3. Dentre os quais, Peck (1999) explica que a escolha da empresa por 
determinadas opções de distribuição depende do valor do produto pago pelo consumidor final, sendo que para que a empresa tenha êxito é preciso criar uma cadeia de suprimentos mais efetiva, que a de seus concorrentes. Assim, as empresas precisam saber como direcionar e criar uma rede de entrega de valor, que supere a atual.

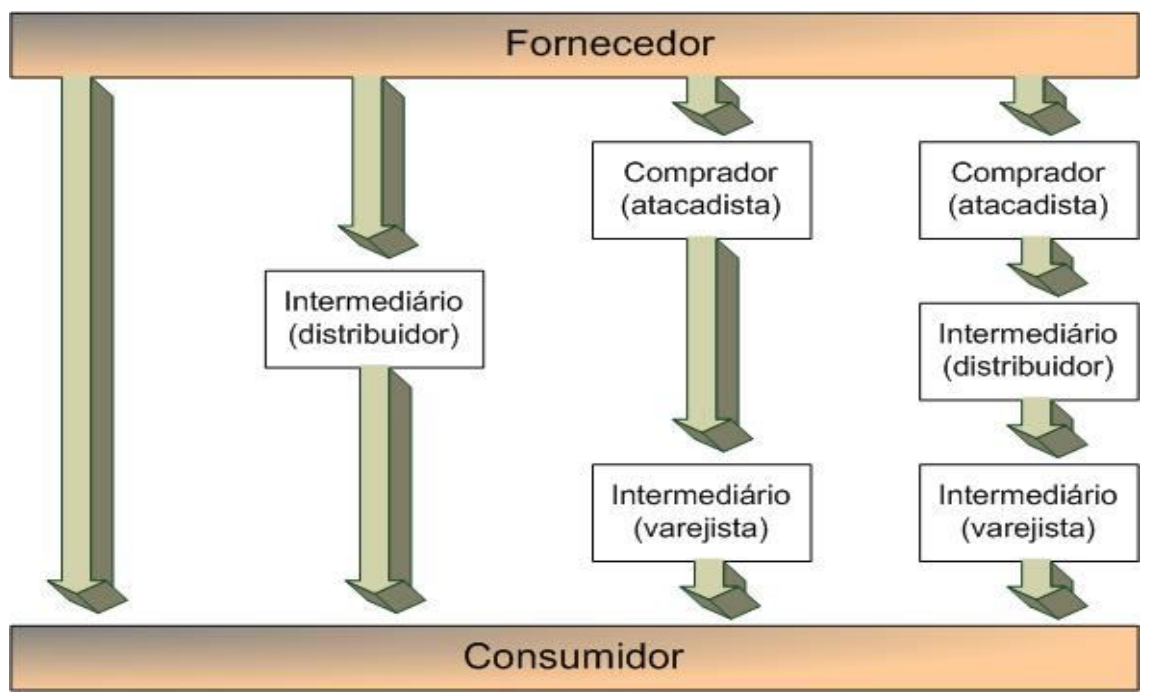

Figura 3 - Opções de canais alternativos na rede de entrega de valor. Fonte: Peck (1999, p.36)

As situações práticas que envolvem as opções de canais de distribuição, mencionadas na figura 3 , podem ser ilustradas da seguinte forma:

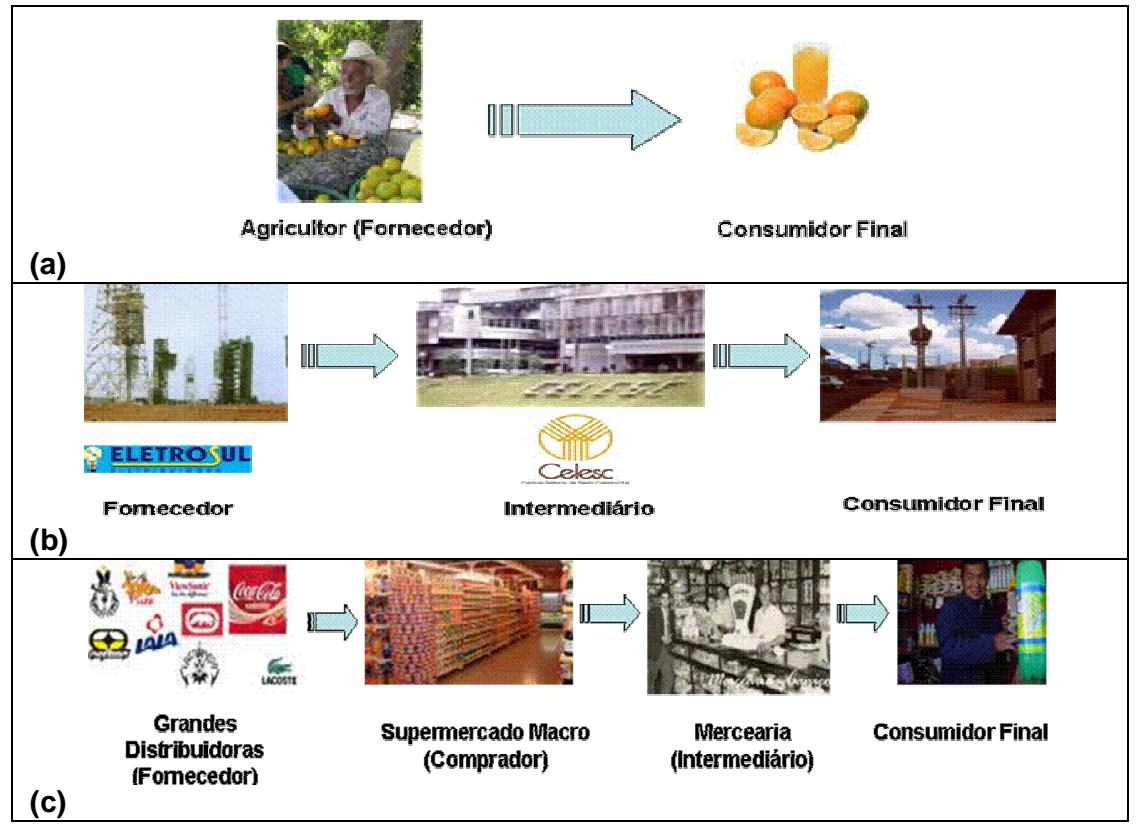




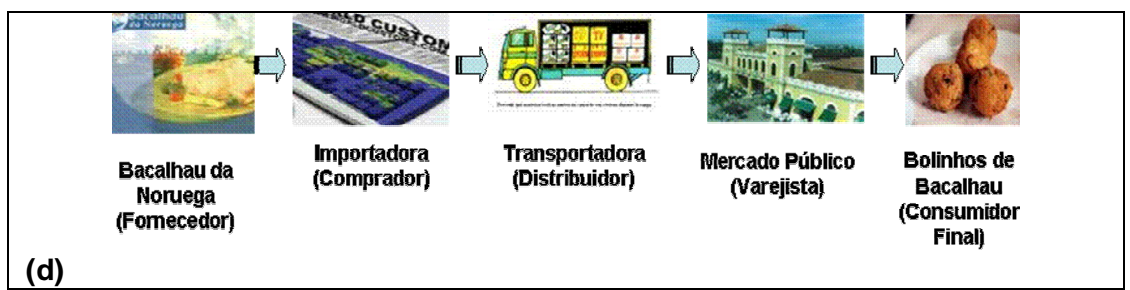

Figura 4 - exemplos de opções de canais de distribuição.

Fonte: autoras.

A situação (a) apresenta $\circ$ agricultor que produz 0 alimento e vende diretamente ao consumidor. O exemplo (b) apresenta uma empresa geradora de energia elétrica, a qual fornece para uma distribuidora, que atende ao consumidor final. O caso (c) ilustra diferentes empresas de distribuição, as quais fornecem produtos aos supermercados macro (atacadista), que abastecem a pequenos estabelecimentos (varejistas), que por sua vez atendem ao consumidor. E, finalmente, a situação (d) da empresa importadora, que compra bacalhau na Noruega, depende da empresa distribuidora, que atende os mercados de peixe, comercializando ao consumidor final.

Nesta perspectiva, Vavra (1993, p.47-48) complementa afirmando que os varejistas e fabricantes não devem mais ser considerados a principal força na estrutura hierárquica, conforme ilustra a figura 5(a).

Ao contrário, o sistema de informação de clientes (banco de dados) e os clientes unificarão o esforço, coordenando o processo de marketing completo e todas as entidades que participam do negócio, conforme ilustra a figura $5(b)$.



(a) Estrutura hierárquica



(b) Esforço coordenado

Figura 5 - Relacionamentos com clientes

Fonte: Vavra (1993, p. 48) 
Conforme Gonçalves et al. (2002, p.37) a principal finalidade é auxiliar aos profissionais e usuários da área de marketing a armazenarem informações, disponibilizando-as sempre que solicitadas. Os autores enfatizam a importância do gerenciamento dos bancos de dados, como recurso para procura, recuperação, geração de relatórios, dentre outras formas de trabalhar a relação de dados disponíveis, para assim gerar estratégias para melhorar o relacionamento com os clientes.

Ainda em se falando de banco de dados, Vavra (1993, p.63) e Gonçalves et. al (2002, p.45) explicam que embora existam muitos grupos específicos de clientes, geralmente quatro devem ser incluídos no banco de dados de clientes:

Os clientes atuais que devem ser identificados pela freqüência de compra, volume médio de pedido, valor de manutenção e tempo da última compra. Os clientes potenciais são identificados pela empresa, mediante o conhecimento dos clientes atuais. Os clientes esquecidos ou perdidos, embora estejam além de objetivo imediato da retenção, podem ainda ser mantidos para receber comunicações,

As informações relacionadas aos clientes de lojas, revendedores ou intermediários são derivadas das compras de clientes. Indiretamente, informações como preferência por departamentos diferentes, lojas, filiais ou revendedores, ou a atratividade das linhas de produtos oferecidas podem ser derivadas dos registros de compra de clientes identificados no arquivo.

Finalmente, Peck (1999) acrescenta o fato das novas oportunidades estarem surgindo, devido aos avanços da tecnologia da informação e computação, apresentando como resultado novos canais para a comercialização. O autor cita a internet como o exemplo mais relevante, sendo que se espera que este canal de distribuição cresça drasticamente durante os próximos anos. O desejo das empresas por construir relacionamentos duradouros com seus clientes possibilitará o desenvolvimento de novos canais, buscando aprimorar o valor dos clientes. 


\section{SEGMENTAÇÃO E ANALISE DO DOMÍNIO DE MERCADO DE CLIENTE}

\subsection{Segmentação do mercado}

No que se refere ao modelo de comportamento do consumidor, tendo o objetivo de analisar a maneira como os indivíduos "ordenam os fatos e as influências para tomar decisões que são lógicas e consistentes para eles durante o processo de compra", o modelo de Engel, Blackwell e Miniardi apresenta sete estágios para a tomada de decisão, as quais: reconhecimento da necessidade, busca de informações, avaliação de alternativas na pré-compra, compra, consumo, avaliação pós-consumo, e descarte. (BLACKWELL et al., 2005)

De acordo com Peck (1999), a segmentação do mercado é o processo de dividir um mercado genérico amplo em vários grupos pequenos, baseados em características ou respostas de clientes nesses segmentos. No passado muita segmentação de mercado foi feita usando segmentos muitos gerais; em alguns casos organizações não empreenderam nenhuma segmentação real de mercado.

Conforme Swift (2001) os métodos tradicionais de segmentação de marketing (demográfico, psicográfico, geodemográfico e agrupamentos comportamentais) até o momento, estão apenas começando em algumas organizações, não sendo o suficiente. O autor afirma que a utilização dos métodos tradicionais de segmentação não possibilitam a reflexão das informações específicas de clientes. Isto se dá porque dentro de um mesmo segmento os clientes podem apresentar diferentes comportamentos de compra.

Peppers e Rogers (1994) também acreditam que características demográficas tais como idade, sexo e renda não são o bastante para diferenciar ou agrupar clientes. É necessário conhecer realmente os clientes, suas atitudes, valores, crenças e estilos de vida.

Gonçalves et al. (2002), baseados em Kotler, sugerem algumas variáveis típicas de segmentação, a serem consideradas para perceber com clareza as características do consumidor, conforme ilustra o quadro 1.

\begin{tabular}{|l|l|}
\hline \multicolumn{1}{|c|}{ Variáveis } & \multicolumn{1}{c|}{ Desdobramentos Típicos } \\
\hline Grupo - Geográfica & \\
\hline Região & Sul, Norte, Sudeste - RJ, Sudeste - SP \\
\hline Tamanho do município & Faixas populacionais: até 5000, 10000, 20000, 50000,
\end{tabular}


ISSN 1676 - 1901/ Vol. 7/ Num. 3/ Novembro 2007

\begin{tabular}{|l|l|} 
& 200000 ou mais habitantes \\
\hline Tamanho da cidade & Dimensões do município em área urbana e rural \\
\hline Concentração & Maioria da população urbana, suburbana, rural \\
\hline Clima & Tropical, Subtropical \\
\hline Grupo - Demográfica & Abaixo de 6, 6-11, 12-19, 20-34, 35-49 \\
\hline Idade & Masculino, Feminino \\
\hline Sexo & 1-2, 3-4, 5 ou mais \\
\hline Tamanho da família & $\begin{array}{l}\text { Jovem/solteiro; filho mais jovem abaixo de seis anos ou } \\
\text { mais; recém-casado; casado com filhos pequenos; } \\
\text { casado com filhos morando fora; casado com filhos } \\
\text { adultos; viúvo; outros }\end{array}$ \\
\hline Ciclo da vida familiar & Faixas típicas de renda familiar ou individual \\
\hline Renda & $\begin{array}{l}\text { Profissional liberal; técnico; gerente; funcionário } \\
\text { público; proprietário; funcionário de escritório }\end{array}$ \\
\hline Nível de escolaridade & $\begin{array}{l}\text { Primeiro grau completo; primeiro grau incompleto; } \\
\text { segundo grau completo;superior completo; superior } \\
\text { incompleto; pós-graduado latu sensu; pós-graduado } \\
\text { strictu sensu, pós-graduado no exterior }\end{array}$ \\
\hline Religião & Identificação da religião \\
\hline Raça & Identificação racial \\
\hline Nacionalidade & Brasileira, Norte-americana, Inglesa \\
\hline Grupo - Psicográfica & \\
\hline Classe Social & Classe A, B, C, D ou E (critérios do IBGE, por exemplo) \\
\hline Estilo de vida & $\begin{array}{l}\text { Metódicos, impulsivos, intelectuais, esportivos, pouco } \\
\text { ou muito sociável }\end{array}$ \\
\hline Personalidade & Compulsivo, sociável, autoritário, ambicioso. \\
\hline Grupo - Comportamental & Compra em ocasião normal; ou em ocasião especial \\
\hline Ocasião de compra & Qualidade, serviço, economia \\
\hline Grupo - Demográfica & Não-usuário, ex-usuário, usuário potencial \\
\hline Benefícios procurados & Pouca utilização, média utilização, grande utilização \\
\hline Status do usuário & Nenhuma, média, intensa, absoluta \\
\hline Taxa de uso & Desconhece, conhece, informado, interessado \\
\hline Grau de lealdade & Entusiástica, positiva, indiferente, negativa Marketing \\
\hline Estágio de aptidão & Atitude para com o produto \\
\hline
\end{tabular}

Quadro 1 - Agrupamento de variáveis relativas a clientes

Fonte: Gonçalves et. al (2002, p.132)

De acordo com Peck (1999), esta segmentação precisa ser executada a todos

os níveis do domínio de mercado de clientes, não só com os compradores direitos da organização.

O autor dá exemplo de um grande fabricante internacional de bens de consumo duráveis, que serve mercados internacionais, que pode segmentar seus compradores (os atacadistas para os quais vende direitamente), em vários modos: país, tamanho, volume, nível de sofisticação, propriedade, dentre outros. 
O fabricante também pode segmentar os varejistas (aqueles que compram dos atacadistas) - seus intermediários - de acordo com os seguintes critérios de segmentação: localização, tamanho, tipo de mercadoria na qual é especialista, número de marcas fornecidas, nível socioeconômico, nível étnico, número de filiais, dentre outros.

Finalmente, o fabricante pode ter uma compreensão de seu consumidor final (aquele que compra dos varejistas), mediante a seguinte: renda familiar, nível socioeconômico, tamanho e status social da família, tipo de ocupação, tipo de residência, necessidade para características especiais, dentre outros.

Uma vez determinada a base de segmentação pertinente, os segmentos de mercado da cadeia de distribuição podem ser identificados. Desta forma, estes segmentos permitirão identificar as oportunidades que podem ser oferecidas diferenciadamente, bem como, identificar os segmentos mais atraentes e o desenvolvimento de estratégias apropriadas para ganhar e reter clientes.

$\mathrm{O}$ autor complementa afirmando que muitas empresas que adotam o Marketing de Relacionamento estão buscando empreendimentos específicos, para a segmentação do mercado alvo. Exemplifica com as organizações que estão migrando para um segundo nível de segmentação de sub-mercado, para praticarem a micro-segmentação, ou seja, comercializar focando num "segmento de consumidores". Exemplo: TESCO PLC, a cadeia principal de supermercados no Reino Unido, que introduziu um cartão de fidelidade chamado o TESCO CLUBCARD, que permite a "personalização da massa", ou seja, a individualização do consumidor final.

Stone e Woodcock (2002), explicam que muitos fornecedores cometem o erro de reunir enormes volumes de dados sobre as necessidades dos clientes. Esses dados geralmente demonstram que os clientes têm grande variedade de necessidades. Os autores apresentam uma hierarquia de segmentação, que segundo eles pode ser útil para determinar os alvos de clientes:

- segmentação analítica: permite analisar as informações acerca do cliente e do mercado, para determinar e identificar a existência ou não de diferentes grupos de clientes, com perfis e necessidades diferentes; 
- segmentação pela reação: permite identificar os diferentes grupos de clientes com o objetivo de direcionar promoções específicas;

- segmentação estratégica: permite identificar os grupos de clientes que precisam, de alguma forma, ser administrados de formas diferentes;

- segmentação pela lealdade comprovada: é um caso especial, no qual identifica-se os grupos específicos de clientes efetivos ou potenciais cuja lealdade é crítica para a empresa.

Concluindo, Gordon (1999, p.29) questiona "como pode o profissional de marketing guiar o relacionamento da empresa com seus clientes, sem um conhecimento relevante e oportuno sobre eles?" O autor esclarece que os profissionais precisam desenvolver sistemas de conhecimento, com o intuito de aprender a respeito de clientes individuais, de modo que as empresas possam criar o valor que cada um deles deseja e estar prontas para servi-los, quando estiverem prontos para comprar.

\subsection{Mapa de mercado}

Segundo Peck (1999) é importante que a empresa considere como um assunto fundamental, dentro do Programa de Marketing de Relacionamento, empreender uma análise de mercado detalhada de cada nível nesta rede de entrega de valor e identificar o tipo de atividade de marketing que precisa ser dirigida a cada membro do canal, incluindo os compradores diretos, intermediários e clientes finais.

Novaes (2001) menciona que o conceito de gestão da cadeia de suprimentos diferencia-se da logística integrada pelos seguintes aspectos: ênfase absoluta na satisfação plena do consumidor final; formação de parcerias entre fornecedores e clientes, ao longo da cadeia de suprimentos; abertura plena, entre parceiros, possibilitando acesso mútuo às informações operacionais e estratégicas, cooperação e formação de alianças; aplicação de esforços de forma sistemática e continuada, visando agregar o máximo valor para o consumidor final e eliminar os desperdícios, reduzindo custos e aumentando a eficiência. 
É importante ressaltar que a análise da segmentação e o entendimento das unidades de tomada de decisão dos diferentes níveis, são necessários para determinar a quantia apropriada de despesa de marketing e o esforço que é pertinente a cada nível. A análise da rede de entrega de valor pode ser auxiliada pela construção de um mapa de mercado, que defina: as atividades de distribuição, o volume de produtos e serviços vendidos e os valores de vendas. A figura 6 , ilustra o mapa de mercado mencionado anteriormente.



Figura 6 - Mapa de Mercado com volumes e/ou valores em cada cenário. Fonte: Peck (1999, p. 39), adaptado de Mc Donald e Dunbar (1995)

A quantia relativa do esforço de marketing, apontada a membros de canais diferentes, precisa ser avaliada e modificada regularmente quando necessário. Depois da análise, a empresa pode perceber que há algumas indústrias intermediárias que podem ser membros valiosos dentro do canal, por outro lado, pode encontrar empresas que não apresentam muito valor dentro do canal. A menos que o intermediário esteja acrescentando valor ao Relacionamento de Clientes, pode provar ser um custo desnecessário e pode ser evitado pela empresa.

Muitas organizações estão percebendo que, ao invés de construírem relacionamentos mais fortes com consumidores finais, precisam mudar a ênfase dos gastos nos diferentes níveis do canal, de modo que construam relacionamentos duradouros.

O fabricante pode decidir revisar sua abordagem de marketing e implementar uma estratégia de marketing alternativa, que focalize mais de perto as necessidades dos consumidores. Isto possibilita identificar os consumidores finais, através de 
cartões de fidelidade ou algumas formas de promoção direita, questionário para ajudar a identificar sua necessidade, call center, clube de clientes, e outros. Estas e outras opções podem ser consideradas como meios para construir relacionamentos com os consumidores finais.

O autor cita um exemplo da General Electric's (GE), organização que construiu um relacionamento mais íntimo com seus consumidores finais, através do estabelecimento de seu maior centro de chamadas telefônicas (call center). O Centro de Resposta GE's é considerado como um dos melhores do mundo. Estabelecido desde 1981 o centro de chamadas busca personalizar GE ao consumidor e personalizar o consumidor a GE, fornecendo seu número telefônico a seus consumidores finais.

Wayland e Cole (1997, p.23) resumiram como o Centro de Resposta GE's contribuiu a acrescentar valor no relacionamento com os clientes, em três áreas fundamentais:

Primeiro, solucionando problemas imediatos numa taxa de probabilidade de reaquisição de 80 por cento para o cliente previamente insatisfeito, comparada com $10 \%$ dos clientes insatisfeitos, mas que não se queixam e 27 por cento para um cliente comum. Em outras palavras, GE tem mais oportunidades para conquistar os clientes insatisfeitos e fortalecer os relacionamentos.

Segundo, o contato com o call center aumenta possibilita que o cliente esteja mais consciente das estratégias da GE.

Finalmente, o conhecimento que é gerado através das interações com os clientes se reverte em valiosa contribuição para as vendas, marketing, e processos de desenvolvimento de novos produtos.

O fracasso de muitos fabricantes, ao desenvolver relacionamentos com seus consumidores finais é bastante comum. Os consumidores podem ficar desapontados, por exemplo, quando buscam reparar um motor de carro diretamente com o fabricante e percebem que o mesmo não está interessado em dialogar.

Swift (2001) explica que a diferença do relacionamento one-to-one está na personalização, ou seja, na geração da realimentação dos clientes, de modo que os profissionais de marketing possam aprender mais a respeito das preferências dos clientes. Desta forma, estas preferências servem de base para ajustar ofertas de produtos, embalagens, entregas, comunicações, ou mesmo os pedidos. 
Ressalta-se que o conceito do Marketing one-to-one segundo Swift (2001, p.305) engloba quatro elementos chaves: identidade, diferenciação, interação e personalização.

A figura 7 ilustra quatro experiências de cliente one-to-one.
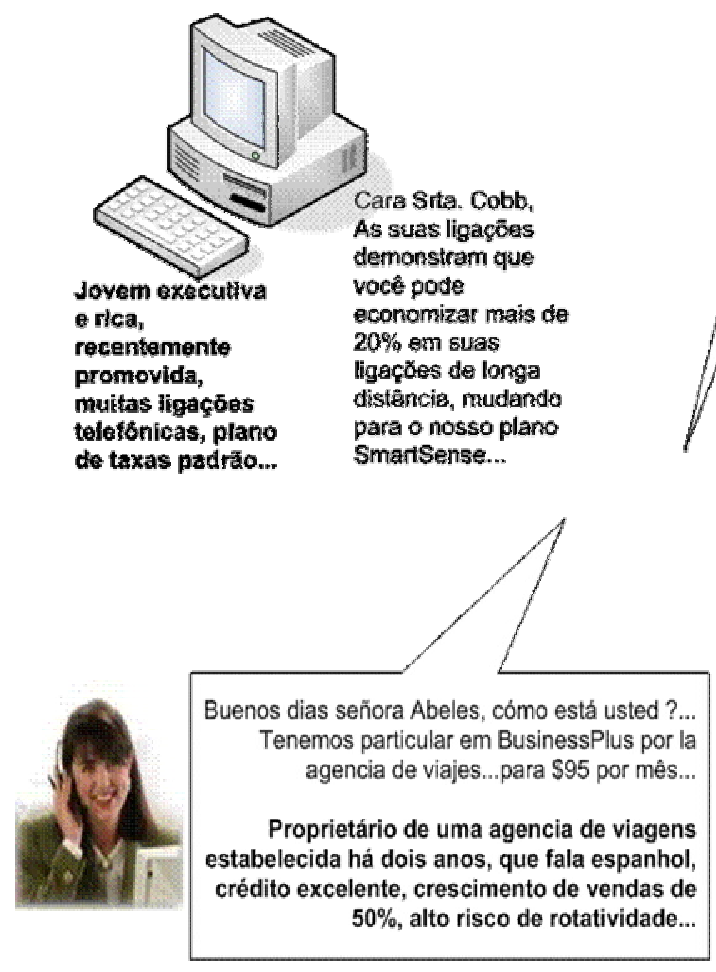

Aló! Sr. Wright, sabemos que o senhor está ocupado e ligamos somente para solicitar descuipas pela ligação interrompida que o senhor experimentou hoje e para informá-lo de que estamos the dando 30 minutos de crédito na próxima fatura...

Associado do Clube Platina Serviço de limusine com um filho na escola...

Figura 7 - Comunicações de marketing com clientes one-to-one Fonte: Swift (2001, p. 306)

Outras companhias também estão repensando sua estratégia de marketing e estão desenvolvendo relacionamentos diretos com o consumidor. A empresa Procter and Gamble está focalizando sua atenção em desenvolver relacionamentos diretos com os consumidores, através de promoção de resposta direta; com sua marca de fraldas Pampers. Aos consumidores é oferecida a oportunidade de obter descontos, completando um cupom que provê informação valiosa como nome, endereço, número telefônico, número de filhos e sua idade. Isto Ihes permite localizar as necessidades dos consumidores mais de perto e fazer ofertas apropriadas e oportunas a eles. Muitos outros fabricantes dentro do setor de varejo estão olhando agora para estas atividades com interesse (KOTLER, 1998). 


\subsubsection{Recursos para sistemas de relacionamentos}

Com a finalidade de desenvolver e acompanhar o relacionamento desejado com os futuros e atuais clientes, Gonçalves et. al (2002) aponta os principais meios aplicados ao marketing de relacionamento, conforme detalha o quadro 2 .

\begin{tabular}{|c|c|}
\hline Sistema / recurso & Descrição \\
\hline Mala direta & $\begin{array}{l}\text { Sistema de mídia através de correspondência, uso de } \\
\text { sistemas de correio físico. }\end{array}$ \\
\hline Telemarketing & $\begin{array}{l}\text { Uso de sistemas de telefonia ativo/receptivo para } \\
\text { desenvolvimento de vendas, através de instalações } \\
\text { próprias ou de call centers ou contact centers (nomes } \\
\text { dados a instalações de telefonia massificada apoiada } \\
\text { em recursos de comunicação e informatica). } \\
\end{array}$ \\
\hline TV interativa & $\begin{array}{l}\text { Uso de recursos de comunicação interativas usando } \\
\text { TVs para apoio a vendas - Teletransmissão. Os recursos } \\
\text { de bidirecionalidade (ou seja, de participação do } \\
\text { espectador, } \\
\text { ampliando a simples recepção de notícias e informações) } \\
\text { está ainda no seu início, havendo de se acertar diversos } \\
\text { requisitos, como a velocidade, conteúdo, segurança, etc. } \\
\text { Alguns sistemas existentes ainda estão restritos a } \\
\text { localidades, hotéis, parques, etc. }\end{array}$ \\
\hline Redes computacionais: & $\begin{array}{l}\text { Redes internas nas empresas - intranets. Redes públicas, } \\
\text { privadas, externas - internet. Redes públicas como a } \\
\text { Internet } \\
\text { em Internet, sentido amplo (e-mail marketing, marketing } \\
\text { eletrónico, etc.) }\end{array}$ \\
\hline Vendas pessoais & $\begin{array}{l}\text { Uso de recursos pessoais no atendimento direto: face-a- } \\
\text { face } \\
\text { com o cliente para vendas. }\end{array}$ \\
\hline Varejo eletrônico & $\begin{array}{l}\text { Uso de sistemas baseados em mídia magneto-óticcas, } \\
\text { como } \\
\text { os CDs, telecomunicações, vendas e distribuição de } \\
\text { produtos a domicílio, como as que são feitas através dos } \\
\text { kits de provimento Internet encartados e oferecidos através } \\
\text { de órganos da mídia. }\end{array}$ \\
\hline
\end{tabular}

Quadro 2 - Recursos para sistemas de relacionamentos

Fonte: Gonçalves et. al (2002, p.125)

Finalmente, Swift (2001, p.7-8) corrobora alertando que "deve ser fomentada uma cultura que capture continuamente informações específicas de clientes, que aumente o seu banco de dados". O autor afirma, ainda, que os conflitos devem ser revertidos em oportunidades para a descoberta de informações adicionais, sendo 
que as mesmas formam a base de um ativo real da empresa - seu relacionamento com os clientes.

\section{UNIDADE DE TOMADA DE DECISÕES}

De acordo com Peck (1999), o fundamental no entendimento do comportamento do cliente é a unidade de tomada de decisões. O conceito da Unidade de Tomada de Decisões (DMU) é importante em todos os níveis dentro da cadeia de distribuição. O Modelo DMU sugere que o cliente inclua vários indivíduos quem têm diferentes papéis no processo de decisão de compra. Estes incluem: os usuários, os que influenciam, os que decidem, os que compram e os guardiães (figura 8).

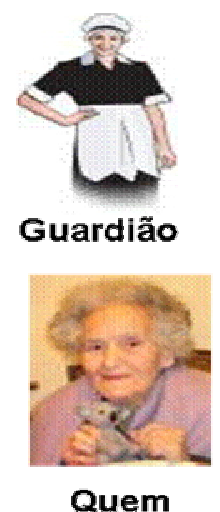

Influencia
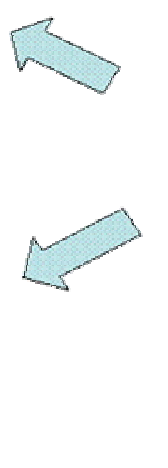

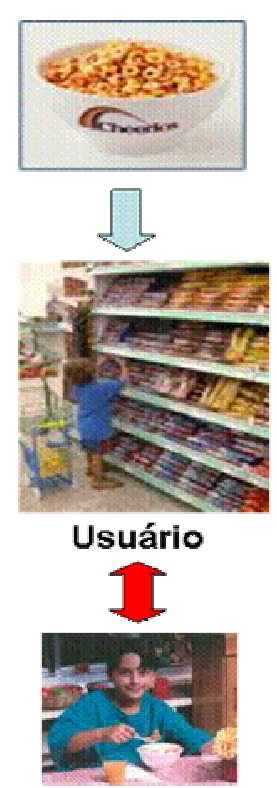

Consumidor Final


\section{Quem Decide}

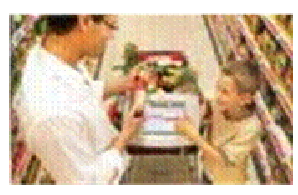

Quem Aprova

e Compra

Figura 8 - Papéis da unidade de tomada de decisão Fonte: autoras

A figura acima ilustra os papéis no processo de compra, com exemplo dos cereais matinais. Os usuários são os membros da organização, que usarão o produto ou serviço. Em muitos casos, os usuários iniciam a proposta e ajudam a definir as especificações do produto. No caso da figura 8 , a criança demonstra interesse por determinado produto, alguns dos atributos podem ser: a caixa de cereal com um brinquedo de brinde, o desenho de super herói, os desenhos 
animados, o desconto de ingresso para filmes em cartaz, dentre outros atrativos. Na decisão de compra há outras pessoas que influenciam, no caso do exemplo tem-se a avó que ajuda na escolha da compra, levando em conta, por exemplo, os fatores nutricionais como as proteínas e os minerais. Têm-se as pessoas que tem o poder de decidir nos requisitos de produto e/ou nos fornecedores. Neste caso, a mãe que leva em consideração a data de validade, o preço, o peso da caixa de cereal, as calorias e adição de açúcar, entre outros. Por outro lado, quem aprova são pessoas que devem autorizar as ações propostas, dos que decidem ou quem compra. Neste caso, o pai é a pessoa que aprova depois da decisão da mãe. Aqueles que compram, são pessoas com uma autoridade formal para selecionar os fornecedores e estabelecem as condições de compra. Podem ajudar na forma das especificações do produto, porém cumprem seu maior papel negociando, mas em compras mais complexas, os compradores poderiam incluir funcionários de um alto nível para participar das negociações. Neste exemplo, o pai é a pessoa que paga efetivamente o produto, de acordo com a decisão da mãe e se é necessário negocia com o vendedor. O guardião exerce alguma função que pode filtrar informações no processo de compra. Neste caso, a empregada pode achar que a embalagem não é apropriada para uso da criança, pode interferir no seu gosto por determinado produto, e inclusive na freqüência de consumo do produto.

Conclui-se que a complexidade do processo de compra pode variar, dependendo da influência de cada membro na decisão de compra. Freqüentemente, o interesse das organizações, em termos do DMU, está em seu cliente mais direto - o comprador. E importante para a empresa saber quem são os membros da DMU e o que eles requerem.

\section{AQUISIÇÃO E RETENÇÃO DE CLIENTES}

Segundo Peck (1999) uma vez determinada a ênfase de marketing apropriada a cada nível dentro do domínio de mercado de cliente, a segunda etapa é a segmentação de mercado e posteriormente, a análise da DMU, para identificar as estratégias de aquisição e retenção de clientes. O foco tradicional de marketing esteve focado no valor da venda individual, porém, esta abordagem transacional foi crescentemente substituída pela abordagem do Marketing de Relacionamento, enfatizando no valor do relacionamento em longo prazo e compras repetidas. $O$ 
quadro 3 descreve um paralelo entre o foco transacional e o foco de Marketing de Relacionamento.

\begin{tabular}{|l|l|l|}
\hline Características & Foco Transacional & Foco de Relacionamento \\
\hline Foco & Obter novos clientes & Retenção de clientes \\
Orientação & Característica de serviço & Valor de clientes \\
Escala de tempo & Curto & Longa \\
Atendimento ao cliente & Pouca ênfase & Alta ênfase \\
Compromisso do cliente & Limitado & Alto \\
Contato com o cliente & Limitado & Alto \\
Qualidade & Interesse em operações & Interesse de tudo \\
\hline
\end{tabular}

Quadro 3 - Foco transacional e foco de relacionamento.

Fonte: Peck (1999, p. 44)

Apesar de uma consciência crescente dos benefícios do Marketing de Relacionamento e retenção, poucas empresas têm conseguido um equilíbrio apropriado entre aquisição e retenção de clientes. Se o atendimento ao cliente não satisfaz suas expectativas, é improvável que o mesmo seja retido e a reputação da empresa pode ser danificada pela negativa publicidade "boca a boca".

De acordo com Peck (1999) a distribuição apropriada de fundos entre a aquisição e retenção de clientes dependerá de vários fatores específicos de indústrias e empresas. Uma empresa em expansão num mercado competitivo precisará investir recursos consideráveis na aquisição de novos clientes, por outro lado, uma empresa bem estabelecida num mercado maduro precisará principalmente focalizar na retenção dos clientes existentes e dos intermediários. Apesar disto, muitas empresas ainda gastam muito recursos, dinheiro e tempo, na aquisição de clientes e muito pouco na retenção.

Conforme Gordon (1999) "a palavra cliente é reservada para os compradores como um todo e representa a audiência total a partir da qual a empresa e seus concorrentes obtêm seus negócios". Neste contexto, Gordon (1999, p. 129-131 apud Gonçalvez et. al, 2002, p.50-51) propõem as categorias descritas na figura 9 , que são subconjuntos do termo cliente, onde fazem uma escala de vínculo, comparando o grau de intensidade do relacionamento versus o processo de compra. 
Escala de Vínculo - Processo de Compra e Intensidade de Relacionamento com o cliente

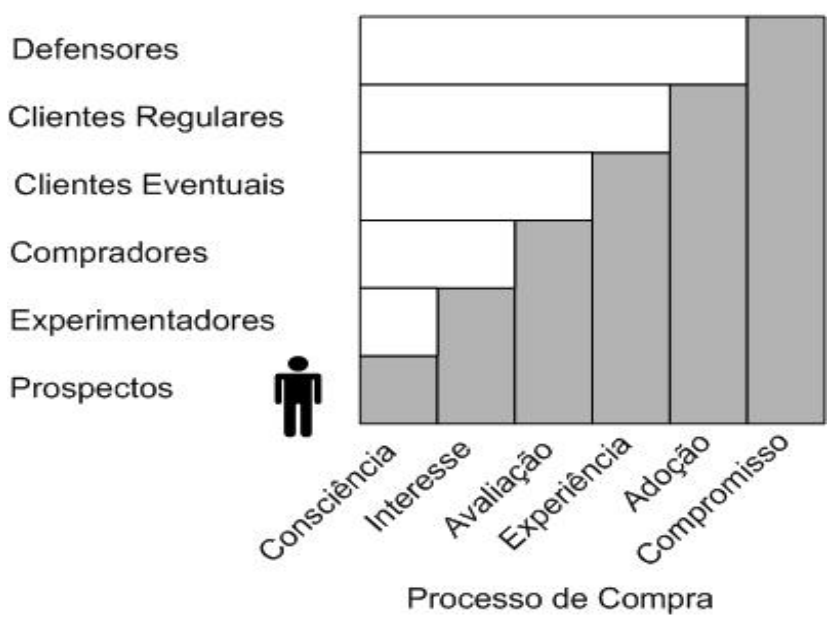

Figura 9 - Clientes e o grau de intensidade do Relacionamento Fonte: Gordon (1999, p. 131)

A seguir, esses vínculos são descritos, progressivamente, a partir do nível mais inferior até o mais elevado.

- Prospectos (clientes potenciais): são pessoas identificadas dentro da população em geral, cujo perfil combina com o que a empresa está procurando.

- Experimentadores: são os prospectos que tomaram conhecimento da organização e das ofertas e começaram a explorar até que ponto a empresa é relevante.

- Compradores: são os experimentadores que estão satisfeitos com sua experiência inicial e passaram a fazer negócios com a empresa, mas não efetivamente.

- Clientes Eventuais: satisfeitos com o período no qual a empresa preencheu suas necessidades, os compradores padronizam aspectos fundamentais de seus processos de compra e aquisições para incluir ua empresa como um fornecedor principal para suas necessidades. Neste estágio você já o 
conquistou, mais ainda não é de sua inteira confiança, já que pode passar a utilizar seus concorrentes ou regredir na escala contínua de vínculo e voltar ser apenas um comprador, ou mesmo parar inteiramente de comprar na sua empresa.

- Clientes Regulares: são aqueles que compram de sua empresa há muito tempo, cuja confiança você conquistou e que adotaram como seus os processos e valores de sua empresa. Eles desejaram se integrar à sua empresa não apenas em seus processos de compras, mas também em outros componentes estratégicos essenciais no negócio.

- Defensores: com eles, a empresa desfruta de clientes regulares tão comprometidos com a organização, que somente uma grave violação de confiança poderia prejudicar essa boa vontade. Um defensor estará sempre ao lado de sua empresa e contará aos outros maravilhas sobre ela. Fará de seu negócio uma referência. Ele trará "boas reclamações", convidando você a melhorar sem ser negativo em suas orientações.

\subsection{Escada para fidelização de clientes}

Peck (1999) apresenta a escada de lealdade de Marketing de Relacionamento, que revela termos parecidos aos expostos anteriormente pelos outros autores, mostrando a evolução dos clientes (compradores, intermediários e consumidores) de fora para dentro da empresa, num caminho que pretenderia acompanhar sua trajetória de não clientes até se tornarem clientes "fiéis". Para tal, o autor dividiu em categorias, como se ilustra na figura 10 , que pretende seguir os passos que desenvolvem este relacionamento numa escala evolutiva. 


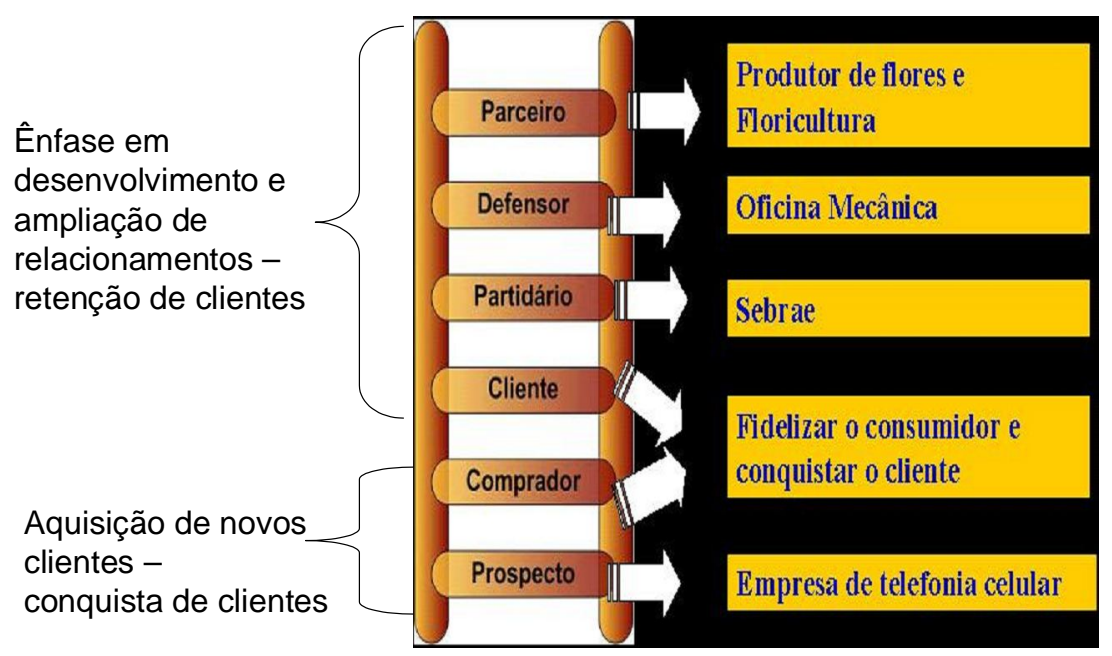

Figura 10 - A escada de lealdade do Marketing de Relacionamento. Fonte: Peck (1999, p. 45)

Entrando na fase de conquista, ou aquisição de cliente, o primeiro passo é tornar o prospecto (cliente viável, aquele que explicita interesse) num comprador (aquele que compra pela primeira vez). O próximo objetivo é transformar o comprador novo num consumidor que compra regularmente (clientes que adquiriram mais vezes um determinado produto) e a partir deste momento inicia-se a fase de fidelização ou retenção de clientes; e então se desenvolve um partidário (só compra seu produto, pesquisa de opinião) da empresa. O próximo avanço na escada de lealdade é um defensor (compra com freqüência e defende a empresa com a publicidade boca a boca). Finalmente, desenvolve um parceiro, onde existe um relacionamento de confiança e compartilhamento mútuo.

Neste processo de fidelização de clientes, segundo Stone (2002, p. 26), a força da publicidade boca a boca e recomendação podem ser tão poderosas dentro do mercado dos clientes, a ponto de influenciar nos membros do processo de decisão de compra. Dado que por meio disto, os clientes satisfeitos ou insatisfeitos comunicam suas experiências a outros.

Cabe ressaltar que, além das categorias mencionadas na figura 10 Gonçalves et al. (2002, p.208) acrescentam na escada de fidelização de clientes os suspeitos, como sendo a primeira categoria a qual "faz parte de um conjunto de consumidores potenciais, dentro de um segmento a ser trabalhado, e que são considerados consumidores genéricos e ainda indecisos". 
Conforme Peck (1999) uma implicação importante da escada de lealdade é que não é necessariamente desejável progredir um relacionamento com todo tipo de cliente; visto que alguns clientes ou segmentos de cliente podem não ser convenientes para que a empresa invista, já que, por exemplo, num relacionamento com um partidário ou defensor, o que demanda investimento freqüente em termos de estratégias de acompanhamento.

Contudo, freqüentemente, pode haver uma necessidade de mudar as atividades de marketing nas organizações e aumentar a despesa de marketing nos elementos que constroem o relacionamento do mix de marketing. Os gerentes, portanto, precisam considerar o potencial do valor de vida do cliente e determinar então se é apropriado fazer o investimento. Neste sentido, há vários exemplos de organizações que investiram muito severamente em aquisição de cliente e acharam então que eles atraíram uma base de cliente que pode ser não lucrativa e que é inapropriada para o desenvolvimento num futuro.

\subsection{Recursos para Aquisição e Retenção de Clientes}

Com o objetivo de obter sucesso nas estratégias de aquisição e retenção de clientes, Gonçalves et. al (2002, p.135) propõem alguns recursos que podem auxiliar, utilizando um exemplo prático para um determinado supermercado.

Cartão de Descontos: concedido aos clientes que atingirem determinadas metas com relação às negociações com o estabelecimento, regularidade na quitação de dívidas, variação em relação ao conjunto de compras e transações feitas.

Histórico de Compras: seria o suporte básico e elementar para a composição dos perfis de clientela, da identificação de um determinado cliente num perfil adequado. Tornaria possível a implementação de um "programa de milhagens", onde, a través da performance da negociação com o supermercado, o cliente receberia bonificações, prêmios, participação em eventos e promoções classificadas.

Regionalização de Ofertas: Direcionadas aos perfis de clientes em que há interesse de aprimorar o relacionamento, motivando-os em termos de suas identidades regionais. Falando em termos brasileiros, podemos abordar a questão 
das alternativas culinárias, de vestuário usual e esportivo, dos hábitos de lazer, entre vários outros.

Compras Centralizadas: Os dados permitiram á gerencia do supermercado que sintonize seus processos de compra a partir de estudos de consumo e de preferências de seus clientes, abordando temas como a sazonalidade de consumo, compras "casadas" (se o cliente consome um artigo provavelmente consumirá outro associado a este primeiro). Desta forma, as compras passam a ser alvo de estratégias mais certeiras, servindo como elemento da cadeia de suprimento e da inserção de valor agregado nas ofertas ao cliente.

Ainda analisando-se este exemplo, pode-se dizer que esses recursos forneceriam informações para o banco de dados de marketing, dentre outras: freqüência e ocasião de suas compras; volume das compras; desejos, necessidades, hábitos; classe, preferências, hobby, estilo; informações geográficas como residência e deslocamentos; grupos de referência e família; idade e ciclo de vida do cliente; ocupação e personalidade; e "life time" do cliente (período em que este irá negociar, segundo seu perfil mercadológico).

\subsection{O valor de reter clientes}

Para Peck (1999) o Marketing de Relacionamento atua como um catalisador do valor de reter clientes. Porém, as pesquisas feitas não exploraram o impacto lucrativo de manter clientes, só reconhecem a importância da retenção dos clientes. Contudo, o autor referencia como evidência disto, uma pesquisa que sugere a existência de uma alta correlação entre retenção de clientes e lucratividade da empresa. Esta pesquisa, feita em diversas indústrias, identificou que até uma pequena melhoria em taxas de retenção (por exemplo, 5\%) poderia fazer um impacto surpreendente na lucratividade, em termos de valor presente, entre $20 \%$ e 125\%, tal como ilustra a figura 11 . 




Figura 11 - Impacto nos lucros com aumento de 5\% na taxa de retenção.

Fonte: Reichheld (1994)

Concluíram que aquele tal efeito surpreendente em lucratividade deveu-se aos seguintes fatores: negócio retido; vendas, marketing e custos de produção estão focados numa vida longa de clientes; aumento do gasto pelo cliente com o passar do tempo; clientes satisfeitos podem ser uma fonte importante de indicações; e clientes satisfeitos tendem a ser menos sensíveis ao preço e podem estar dispostos a pagar um preço maior.

Hoje em dia, os gerentes precisam ter informação para Ihes permitir fazer escolhas em alocação de recursos entre aquisição e retenção de clientes. Neste sentido, Peck (1999), Payne e Rickard desenvolveram um modelo matemático de retenção, que permitiu a alocação dos recursos de marketing entre as duas estratégias, assim como também, o cálculo do impacto da lucratividade dos fatores relacionados a reter e adquirir clientes (figura 12). Entre estes fatores, incluem-se: a taxa de retenção de clientes, número de clientes existentes, aquisição alvo de novos clientes, custo de adquirir cada cliente e, o lucro por cliente por período. Assim mesmo, este modelo foi usado numa gama de indústrias para entender como muda o impacto nas anteriores variáveis, em segmentos de clientes e na lucratividade da empresa. 


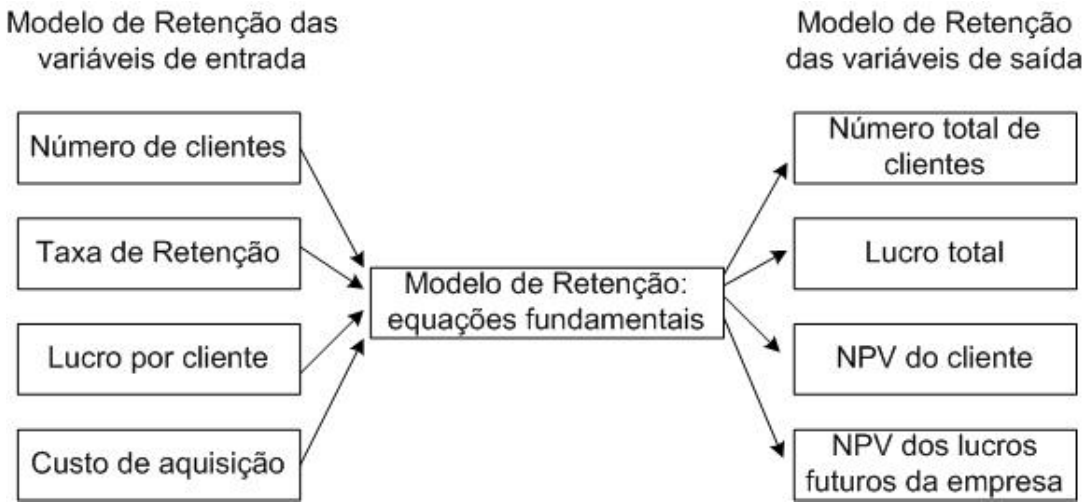

Figura 12 - Modelo de retenção.

Fonte: Peck (1999)

Outros pesquisadores como Ennew e Binks, também estão trabalhando em aspectos de retenção de clientes. Eles examinaram as ligações entre retenção/defecção de clientes e qualidade de serviço, num contexto de relacionamento de clientes no setor bancário do Reino Unido. Os quais encontraram evidenciar as hipóteses que retenção/fidelidade são influenciadas pela qualidade do serviço e pelo relacionamento com o cliente, e descobriram que a confiança nos relacionamentos bancários tem um maior impacto na defecção potencial.

Segundo Peck (1999), outros trabalhos em retenção de clientes foram empreendidos por Page, Bethon e Money, que desenvolveram uma abordagem quantitativa para analisar o comportamento das duas diferentes estratégias (redução na taxa de defecção e melhoria na aquisição de novos clientes); e exploraram a probabilidade do desaparecimento de clientes em função do tempo, para assim direcionar diferentes estratégias do mix de marketing para clientes novos e existentes.

Entretanto, há também fortes evidencias de que os clientes leais são os mais lucrativos, já que tendem a comprar mais serviços e a experimentar os novos, neste sentido, a retenção aumenta junto com a quantidade de produtos adquiridos. Estudos feitos nas empresas com foco na retenção conseguiram melhorias significativas nesse aspecto, retendo até $35 \%$ dos clientes que normalmente teriam ido embora.

De acordo com Swift (2001, p. 80) conclui-se que "o gerenciamento da retenção de clientes é conseguido com uma aguda percepção a respeito de quem 
são seus clientes para, então, se desenvolver e se utilizar modelos que prevejam quais os clientes que provavelmente irão embora", para assim ser capaz de tomar decisões fundamentadas sobre quais clientes deve-se tentar reter e examinar as possibilidades de melhoria dos lucros, para decidir como atender suas necessidades.

\section{CONSIDERAÇÕES}

Neste trabalho explorou-se o papel do domínio de mercado de clientes, que inclui os três grupos essenciais: compradores diretos, intermediários e consumidores finais. Entretanto, destacou-se que a abordagem do marketing tradicional focou só nos compradores diretos - como ganha-los, e que tipo de oferta fazer a eles-, enquanto que substituída pela abordagem de Marketing de Relacionamento, que reconhece que o sucesso com os compradores diretos também depende da gerencia do relacionamento com os intermediários e consumidores finais na cadeia de distribuição. Para desenvolver relacionamentos com o mercado de clientes as empresas precisarão aplicar os seguintes passos fundamentais, dentre as quais revisar a rede de entrega de valor atual, identificando os membros do canal; determinar o uso apropriado do canal, de tal forma que maximize o valor de vida dos segmentos atrativos dentro do grupo de consumidores finais, incluindo o papel das oportunidades da nova distribuição tais como a internet e o comercio eletrônico. Desenvolver estratégias de segmentação apropriadas para cada um dos membros do canal: compradores diretos, intermediários e consumidores finais, de modo que, busquem migrar em direção à micro-segmentação e, em alguns casos, ao marketing um a um. Criar um mapa de mercado como ferramenta de ajuda para entender e definir os volumes e os valores que são vendidos através dos diferentes níveis da rede de entrega de valor, para desta forma, identificar as estratégias a serem implementadas em cada estado da rede. Compreender a unidade de tomada de decisões em todos os níveis da rede de entrega de valor. Revisar regular e detalhadamente a ênfase e gasto de marketing na atração e retenção do cliente, para assim ser administrada da melhor forma. Conduzir pesquisas de mercado à compreensão das razões da defecção de clientes. Determinar as estratégias de marketing apropriadas de retenção e aquisição, já que estas podem ser custosas porque frequentemente envolve níveis crescentes de atendimento ao cliente. E 
importante segmentar os clientes de acordo a seu potencial de lucratividade para depois determinar o tipo de atividade de marketing apropriada para que cada grupo aumente seu potencial. Determinar por meio da Escada de Lealdade no Marketing de Relacionamento, quais clientes ou grupos de clientes desejam progredir e quais deles não, para assim, ter um entendimento geral de quais segmentos produzirão um aumento maior na lucratividade ao melhorar as atividades de retenção. Desenvolver o plano de marketing para o domínio de mercado de clientes, levando em conta, os relacionamentos com os outros domínios de mercado: fornecedores e alianças, internos, de referencia, de influencia, e de recrutamento; como parte do marketing de relacionamento global.

Concluindo-se, as palavras colocadas por Swift (2001) relembram da importância do Relacionamento com o cliente. Para o autor, com a ampliação do papel dos clientes nos relacionamentos, os fornecedores ou provedores de serviços têm se preparado para servi-los e atender suas necessidades na troca pelo valor (lucrativo), em forma de dinheiro e negócios repetidos, permitindo o benefício mútuo no relacionamento.

\section{REFERÊNCIAS}

Blackwell; Miniard; Engel. Comportamento do Consumidor. São Paulo: Pioneira Thompson Learning, 2005.

GONÇALVES, Carlos Alberto; JAMIL, George Leal; TAVARES, Wolmer Ricardo. Marketing de Relacionamento: Database Marketing, uma estratégia para adaptação em mercados competitivos. Rio de Janeiro: Axcel Books, 2002. 329 p.

GORDON, lan. Marketing de Relacionamento: Estratégias, Técnicas e Tecnologias para conquistar clientes e mantê-los para sempre. São Paulo: Editora Futura, 1999. $349 \mathrm{p}$.

KOTLER, Philip. Administração de Marketing: análise, planejamento, implementação e controle. São Paulo: Atlas, 1998.

NOVAES, Antonio Galvão. Logística e Gerenciamento da Cadeia de Distribuição:

Estratégia, Operação e Avaliação. Rio de Janeiro: Campus, 2001. 
PECK, Helen; PAYNE, Adrian; CHRISTOPHER, Martin; CLARK, Moira.

Relationship Marketing: strategy and implementation. Oxford: Butterworth-

Heinemann, 1999.

PEPPERS, D., ROGERS, M. Marketing Um a Um, Rio de Janeiro: Campus, 1994. $329 \mathrm{p}$.

PEPPERS, Don e Martha Rogers. The One-to-One Future: Building Relatioships One Customer at a Time. Nova York: Doubleday, 1996.

RAPP, Stan; COLLINS, Tom. A grande virada do marketing. São Paulo: Futura, 1999.

REICHHELD, F. F. Loyalty and the Renaissance of Marketing Management. Harvard Business Review, vol. 2, Issue 4., n. 71, p. 64-73, 1994.

STONE, Merlin; WOODCOCK, Neil. Marketing de Relacionamento. São Paulo: Littera Mundi, 2002. 197 p.

SWIFT, Ronald. CRM, Customer Relationship Management: o revolucionário marketing de relacionamento com os clientes. Rio de Janeiro: Elsevier, 2001. 493 p.

VAVRA, Terry G. Marketing de Relacionamento after marketing: como manter a fidelidade de clientes através do Marketing de Relacionamento. São Paulo: Atlas, 1993. $323 \mathrm{p}$.

WAYLAND, R.E. e COLE, P.M. Customer Connections: New strategic for growth, Boston: Harvard Business School Press, 1997. 